\title{
Effects of protein and folic acid intake in rat pregnancy on availability of methyl donors in maternal and fetal plasma and liver at day 20 of gestation
}

\author{
Sarah Engeham and Simon Langley-Evans \\ University of Nottingham, Nottingham, UK
}

Nutritional insult during pregnancy is widely accepted to have the capacity to programme permanent alterations in tissue structure and function ${ }^{(1)}$. A low-protein diet during pregnancy has been shown to alter gene expression in tissues such as the liver, and supplementation of the maternal diet with folic acid reverses this alteration ${ }^{(2)}$. It has been suggested that a perturbation in the methonine-homocysteine and folate cycles, associated with low-protein feeding, may lead to hypomethylation of DNA and dysregulation of gene expression and metabolism $^{(3)}$. The aim of the present study was to investigate the extent to which a low-protein diet in rat pregnancy might impact on availability of methyl donors in maternal and fetal liver.

Twenty-four virgin female Wistar rats were mated at a weight of 180-220 g. On confirmation of mating the rats were fed one of four diets: control (CP; $180 \mathrm{~g}$ casein/kg diet with $1 \mathrm{mg}$ folic acid/kg; $n$ 6); control with folate (CPF; $180 \mathrm{~g}$ casein/kg diet with $5 \mathrm{mg}$ folic acid/ $\mathrm{kg} ; n$ 6); low protein (MLP; $90 \mathrm{~g}$ casein/kg diet with $1 \mathrm{mg}$ folic acid/kg; $n$ 6); low protein with folate (MLPF; $90 \mathrm{~g}$ casein/kg diet with $5 \mathrm{mg}$ folic acid $/ \mathrm{kg} ; n$ 6). At day 20 of gestation the rats were killed and pups and placentas were removed, the pups killed and pups and placentas weighed. Maternal and fetal blood and liver were collected. Folate and homocysteine were measured in maternal and fetal plasma (fetal plasma was pooled for each litter). Folate and choline were measured in maternal and fetal liver (one male and one female fetus from each litter).

Circulating homocysteine levels in the maternal and fetal plasma were unaffected by maternal protein or folate intake during pregnancy. Circulating folate levels in fetal and maternal plasma were also unaffected by maternal protein, but were significantly increased by maternal folate intake during pregnancy $(P=0.001$ and $P<0.001$ respectively). Folate content of the maternal liver was also increased by folate supplementation, but was unaffected by protein intake $(P<0.001)$. Folate content of the fetal liver was unaffected by protein or folate intake. Choline in the fetal and maternal liver was increased in the MLP group, but folate supplementation abolished this increase $(P=0.03$ and $P=0.057$ respectively for folate $\times$ protein interaction). Phosphocholine was increased by folate supplementation in the maternal liver only $(P=0.029)$.
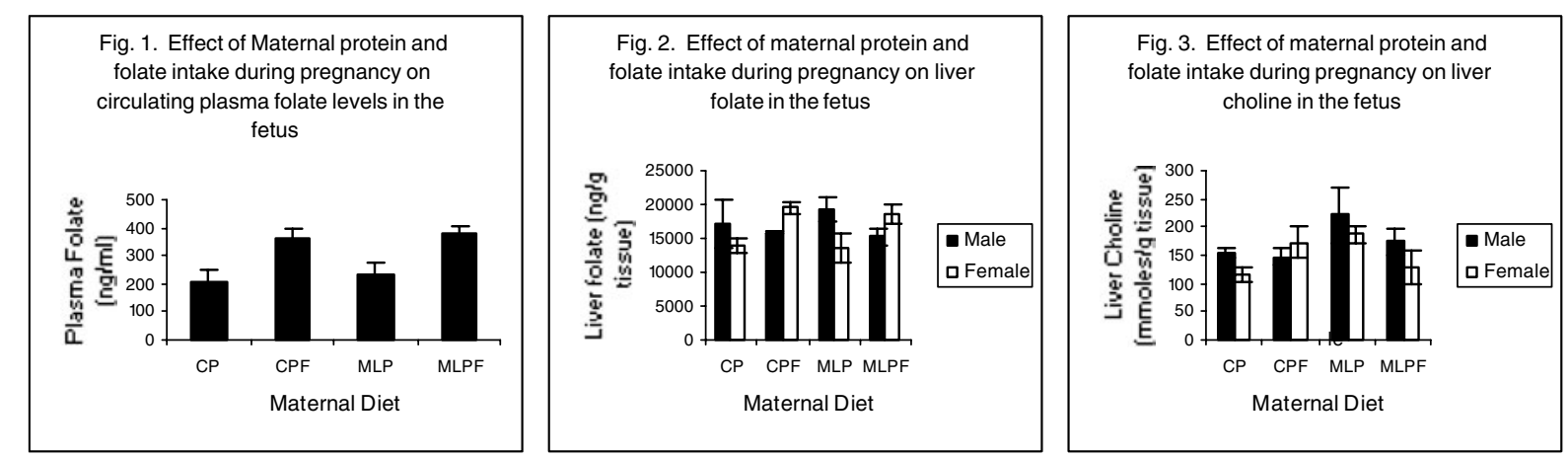

Data in Figs. 1-3 are means with their standard errors represented by vertical bars for four to six fetuses per gender per group. The effect of maternal folate intake on circulating plasma folate was significant (ANOVA; $P=0.001$ ). There was no effect of maternal diet on fetal liver folate. Fetal liver choline was influenced by an interaction of protein $\times$ folate $(P=0.03)$.

In contrast to other studies ${ }^{(3)}$, the present work has shown that a maternal low-protein diet does not impact on either maternal or fetal homocysteine, or folate availability. Supplementation of folate leads to a major increase in circulating folate in the fetus. This treatment appears to alleviate programming changes attributable to the low-protein diet ${ }^{(2)}$. However, this beneficial effect must occur through mechanisms unrelated to substrate availability.

1. Langley-Evans SC (2006) Proc Nutr Soc 65, 97-105.

2. Lillycrop KA, Phillips ES, Jackson AA, Hanson MA \& Burdge GC (2005) J Nutr 135, 1382-1386.

3. Petrie L, Duthie SJ, Rees WD \& McConnell JML (2002) Br J Nutr 88, 471-477. 